\title{
An observational, prospective and questionnaire-based study to assess awareness of pharmacovigilance among resident doctors in a tertiary healthcare centre of Bihar
}

\author{
Purnendu Arya $^{1}$, Hitesh Mishra ${ }^{2}$, Manish Kumar ${ }^{3}$, Adil Ali Shakur ${ }^{4 *}$, Lalit Mohan ${ }^{5}$, Harihar Dikshit ${ }^{6}$ \\ ${ }^{1}$ Junior Resident (PGT- Final Year), ${ }^{2,5}$ Additional Professor, ${ }^{3}$ Associate Professor, ${ }^{4}$ Senior Resident, ${ }^{6}$ Professor and Head, \\ Dept. of Pharmacology, Indira Gandhi Institute of Medical Sciences, Patna, Bihar, India
}

*Corresponding Author: Adil Ali Shakur

Email: adilshakur04@gmail.com

\begin{abstract}
Background: Adverse Drug Reactions (ADRs) is a global health problem requiring attention of healthcare professionals. Healthcare professionals are backbone of pharmacovigilance programme and hence have a major role for better healthcare system.

Aim: To assess the awareness of knowledge and practice of pharmacovigilance among residents in our health set-up.

Materials and Methods: An observational, prospective and questionnaire-based study comprising 15 questions pertaining to Pharmacovigilance. 60 Residents (30 junior and 30 senior residents) from different clinical departments were sampled. Questionnaire was based on two alternative answers viz "Yes" or "No". Questions were further segregated into four classes for evaluation of awareness in different spheres of pharmacovigilance. A grading scale was used to determine the awareness of residents about pharmacovigilance.

Statistical Analysis: Wilcoxon matched-pairs test using GraphPad Instat software.

Results: This study was conducted in two visits. After second visit there was significant increase in response in which education encompassing pharmacovigilance was recommended by $61.66 \%$ of residents. Percentage of residents responding "yes" regarding established independent body for reporting of ADRs was $48.33 \%$. Further, evaluation of awareness in different spheres of pharmacovigilance showed that fundamental knowledge of pharmacovigilance among residents was excellent in $21.66 \%$, good in $45 \%$, average in $10 \%$ and poor in $25 \%$ of the residents.

Conclusions: Knowledge and practice of pharmacovigilance was improved among residents after giving proper sensitization. Hence, improved perception can remove the misconceptions, obstacles and barriers in practice of pharmacovigilance. Furthermore, large-scale awareness of pharmacovigilance is required among different healthcare professionals for better understanding of this system.
\end{abstract}

Keywords: Grading Scale, Knowledge, Practice, Questionnaires, Sensitization.

\section{Introduction}

Drug is an important aid for treatment of any disease and has many beneficial effects. However, they are like double edged swords; on one hand drugs cure, prevent, manage or diagnose diseases, but on the other hand they also have potential of causing harm in form of Adverse Drug Reactions (ADRs) which are some of its major disadvantage. ${ }^{1}$ ADR is defined by World Health Organization (WHO) as "a response to a drug which is noxious and unintended and which occurs at doses normally used in man for prophylaxis, diagnosis or therapy of disease or for the modification of physiological function. ${ }^{2}$ Higher incidence of ADRs is a global health problem requiring attention of all stakeholders regardless of the practice settings. ${ }^{3,4}$ It has been observed that drug induced conditions lead to $5 \%$ of all hospital admissions and $10-20 \%$ of hospitalized patient develops ADRs with consecutive impact on health care cost. $^{5-8}$ In order to promote drug safety, WHO started Program for International Drug Monitoring in 1968 and subsequent to that it promoted pharmacovigilance program at country level in collaboration with Uppsala monitoring Center (UMC) for International Drug Monitoring in 1978. In India, in the year 2010, the Central Drug Standard Control Organization (CDSCO) under the aegis of ministry of health and family welfare, Government of India launched nationwide Pharmacovigilance Program of India (PvPI) and made Indian Pharmacopoeia Commission (IPC) as National Coordinating Centre (NCC). ${ }^{9}$ Pharmacovigilance, a vital science in field of drugs is there to detect and spontaneously report ADR to ensure patient's safety. Pharmacovigilance seeks to improve patient care and safety in relation to the use of drugs and to contribute in the assessment of benefit, harm, effectiveness and risk of drugs. Healthcare professionals are backbone of pharmacovigilance program and hence have a major role in it. ${ }^{10}$ Spontaneous reporting is one of the cornerstones of pharmacovigilance system which involves active participation of reporters in detection and reporting of ADRs. However, currently ADR reporting does not appear to be a part of routine practiced by healthcare professionals and is a major drawback of this system. ${ }^{11,12}$ In India, like many other developing countries pharmacovigilance activities are being faced with a number of challenges such as underreporting of ADRs and sustaining the reporting culture. Ignoring the importance of documenting and reporting ADRs by healthcare professionals leads to recurrence of preventable drug-related morbidity and mortality. As noted in previous studies, most ADRs causing hospital admissions are due to commonly used medications and are mainly preventable. ${ }^{13} \mathrm{~A}$ study also showed that only 6-10\% of all ADR cases are reported. ${ }^{14,15}$ Sensitizing healthcare professionals by imparting adequate knowledge and skill could play a major role and bring a paradigm shift in successful implementation of pharmacovigilance program. ${ }^{16,17}$ The success of pharmacovigilance activities is heavily reliant on the participation of healthcare professionals as they perform their daily duties of diagnosis, prescribing and monitoring 
of patients. Their opinions and attitudes regarding ADRs are inevitable component in pharmacovigilance as they contribute towards the build-up of ADR data. ${ }^{18}$ On the basis of such generated data regulatory bodies can take decision on the use of drugs posing threat to safety of patients. Reporting of ADRs is a voluntary act and not mandatory for healthcare professionals therefore under these conditions awareness regarding reporting of ADRs should be assessed and if not found up to appropriate level, then some corrective measures should be taken in terms of campaigning or training programs for the same. ${ }^{19}$

Numerous studies have been done previously to assess the knowledge and practice of pharmacovigilance amongst healthcare professionals, but very few studies have been done among the resident doctors to assess their knowledge which is essential as patients are commonly firstly attended by the residents perpetually. Data is sparse on the role of sensitization and awareness activities to improve the same. Hence, this study has been done to assess the knowledge and practice of pharmacovigilance among junior and senior residents of our institute to compare the result among them and the role of sensitization on the same.

\section{Materials and Methods}

This study was an observational and prospective study conducted for a period of 18 months i.e. from February 2018 to July 2019. A questionnaire comprising of 15 questions pertaining to pharmacovigilance was prepared. Convenient and purposive sampling methods were applied, whereby resident doctors of our institute were approached and asked to participate in this study. This allowed recruitment of participants who were readily available to give information on pharmacovigilance practice in our hospital. A total of 60 Residents (30 junior residents and 30 senior residents) from different clinical departments were conveniently sampled. Questionnaire was distributed to respective two groups' i.e. junior and senior residents with prior permission of the institution. The participants were explained the nature of study and then were asked to fill the questionnaire according to their individual knowledge. They were not allowed to consult their group members for their opinion on any question. The participants were restricted to one sitting without any time constraint, to fill the questionnaire. All the filled in questionnaires were collected, compiled and analyzed.

\section{Questionnaires}

1. Do you know about Pharmacovigilance?

2. Do you know about National Pharmacovigilance Programme?

3. Do you understand the relevance of the term Pharmacovigilance?

4. Are you aware of the aims and objectives of Pharmacovigilance?

5. Do you know where to report an adverse drug reaction?

6. Are you aware of the various interventions to prevent adverse drug reactions?
7. Are you aware how to proceed if adverse drug reaction/drugs side effect occurs?

8. After noticing an adverse drug reaction did you intervene to rectify by using suitable measures?

9. Do you expect that Pharmacovigilance will intervene knowledge of treating physician about the medicine?

10. Do you expect that Pharmacovigilance will intervene awareness of right medicine for right indication in right patients?

11. Do you expect any circumstantial benefit in patients care by Pharmacovigilance?

12. Should there be mentioned system in hospitals regarding Pharmacovigilance?

13. Do you recommend integrated approach towards training and education about the Pharmacovigilance in medical institute and general public?

14. Do you think that having an independent body for reporting adverse drug reactions in your institute is beneficial?

15. Should proper recommendations to be instituted in the areas of organization, legislation, regulation and resources to improve surveillance and safe use of drugs?

Every question in the questionnaire was based on two alternative answers viz "Yes" or "No". Questions in questionnaire were further segregated into four classes for evaluation of awareness in different spheres of concept about pharmacovigilance.

First class was designated as class 'A' which comprised of six questions i.e. question no. 1, 3, 4, 6, 7 and 8 which pertains to the fundamental knowledge regarding pharmacovigilance and interventions their-of. Class ' $\mathrm{B}$ ' comprised of questions concerned with the reporting system for pharmacovigilance i.e. question no. 2 and 5. Class ' $C$ ' was constituted of questions pertaining to possible benefits of pharmacovigilance i.e. Question no. 9, 10 and 11 . Similarly, class 'D' was categorized by making a set of questions related to the capability to give constructive opinion/recommendations over the improvement of system for pharmacovigilance i.e. question no. 12, 13, 14 and 15. Every "Yes" response was given score one and every "No" was given score zero and cumulative score was calculated for the whole class of questions. A grading scale was used to determine the awareness of participants about pharmacovigilance (Table 1).

\section{Statistical analysis and data collection technique}

The data were collected in two visits. In first visit, recruited residents were approached and were asked to fill the questionnaires which were entered in Microsoft Excel. In second visit, which was done after five months same residents were approached and were again asked to fill the same questionnaires. Each session on average lasted about 30- 40 minutes. The responses were transcribed verbatim within 48 hours into Microsoft excel. Collected were statistically analyzed by using GraphPad Instat Software. Analysis was done using Wilcoxon matched paired test. One tail $\mathrm{P}$ value was obtained using nonparametric samples. 


\section{Result}

The results had been compiled after completion of visit 01 and visit 02 for each resident.

\section{Visit 1}

Training and education encompassing pharmacovigilance (question no. 13) was recommended by $56.67 \%$ of residents. Percentage of residents responding "yes" regarding established of independent body (question no. 14) for reporting of ADRs was $38.33 \%$. $50 \%$ of residents were recommending the proper recommendation to be instituted in the area of organization, legislation, regulation and resources to improve surveillance and safe use of drugs (question no. 15) as shown in fig. 1.

The result is further segregated into four classes for evaluation of awareness in different spheres of concept about pharmacovigilance as shown in table 2 .

1. It has been observed that knowledge of fundamentals of pharmacovigilance among residents was excellent in $20 \%$, good in $36.66 \%$, average in $13.33 \%$ and poor in $30 \%$ of the residents. $30 \%$ of residents had poor knowledge of pharmacovigilance of which $6.66 \%$ of residents were found to have no basic knowledge and scored zero in class A.

2. The knowledge about the reporting system of pharmacovigilance was excellent in $30 \%$, average in $26.66 \%$ and poor in $43.33 \%$ of residents in class B.

3. Among the residents $28.33 \%$ were excellent, $26.66 \%$ were good, $20 \%$ were average and $25 \%$ were poor regarding knowledge of possible benefits of pharmacovigilance in class $\mathrm{C}$.

4. The response was excellent for $26.66 \%$, good for $26.66 \%$, average for $15 \%$ and poor for $31.67 \%$ of the residents. Out of $31.67 \%$ of respondents having poor knowledge $20 \%$ were found to be incapable of giving any productive recommendation or opinion over the betterment system of pharmacovigilance and fetched a score of zero in class D.
After five months second visit was conducted in which training and education encompassing pharmacovigilance (question no. 13) was recommended by $61.66 \%$ of residents. Percentage of residents responding "yes" regarding established independent body (question no. 14) for reporting of ADRs was $48.33 \%$. $55 \%$ of residents were recommending the proper recommendation to be instituted in the area of organization, legislation, regulation and resources to improve surveillance and safe use of drugs (question no. 15) as shown in Fig. 2.

The result is further again segregated into four classes for evaluation of awareness in different spheres of concept about pharmacovigilance as shown in Table 3.

1. It has been observed that knowledge of fundamentals of pharmacovigilance among residents was excellent in $21.66 \%$, good in $45 \%$, average in $10 \%$ and poor in $25 \%$ of the residents. $3.33 \%$ of residents were found to have no basic knowledge and scored zero in class A.

2. The knowledge about the reporting system of pharmacovigilance was excellent in $33.33 \%$, average in $43.33 \%$ and poor in $23.33 \%$ of residents in class B.

3. Among the residents $28.33 \%$ were excellent, $35 \%$ were good, $25 \%$ were average and $11.66 \%$ were poor regarding knowledge of possible benefits of pharmacovigilance in class $\mathrm{C}$.

4. The response was excellent for $30 \%$, good for $31.66 \%$, average for $15 \%$ and poor for $23.32 \%$ of residents. $11.66 \%$ were found to be incapable of giving any productive recommendation or opinion over the betterment system of pharmacovigilance and fetched a score of zero in class D.

Further, the mean score earned by residents in all four classes of different spheres of concept about pharmacovigilance were compared as shown in table 3 .

After completion of both visits, including study related interventions like; sensitization and training programs it was observed that the average monthly reporting of ADRs had increased. It was found that the average number of reports for three months increased from 29.33 to 51.67 after second visit.

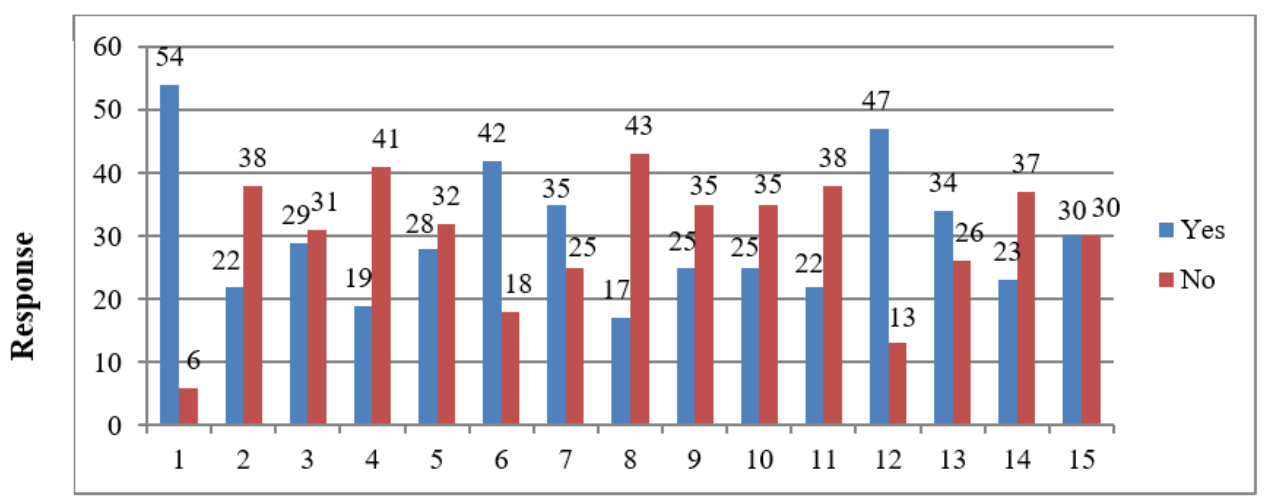

Question number of questionnaires

Fig. 1: Response shown by residents for each question 
Table 1: Grading scale to determine the awareness of residents about pharmacovigilance

\begin{tabular}{|l|c|c|c|c|c|}
\hline Class & Total no. of & \multicolumn{4}{|c|}{ Grading Scale } \\
\cline { 3 - 6 } & questions & Excellent & Good & Average & Poor \\
\hline A & 6 & 6 & 5,4 & 3 & $\leq 2$ \\
\hline B & 2 & 2 & - & 1 & 0 \\
\hline C & 3 & 3 & 2 & 1 & 0 \\
\hline D & 4 & 4 & 3 & 2 & $\leq 1$ \\
\hline
\end{tabular}

Table 2: Score earned by residents in different classes of questions

\begin{tabular}{|l|c|c|c|c|}
\hline $\begin{array}{l}\text { Score } \\
\text { Earned }\end{array}$ & $\begin{array}{c}\text { Class A } \\
(\mathbf{N = 6 0})\end{array}$ & $\begin{array}{c}\text { Class B } \\
(\mathbf{N = 6 0 )}\end{array}$ & $\begin{array}{c}\text { Class C } \\
(\mathbf{N = 6 0})\end{array}$ & $\begin{array}{c}\text { Class D } \\
(\mathbf{N = 6 0})\end{array}$ \\
\hline 0 & $4(6.66 \%)$ & $26(43.33 \%)$ & $15(25.00 \%)$ & $12(20.00 \%)$ \\
\hline 1 & $8(13.33 \%)$ & $16(26.66 \%)$ & $12(20.00 \%)$ & $7(11.67 \%)$ \\
\hline 2 & $6(10.00 \%)$ & $18(30.00 \%)$ & $16(26.66 \%)$ & $9(15.00 \%)$ \\
\hline 3 & $8(13.33 \%)$ & - & $17(28.33 \%)$ & $16(26.66 \%)$ \\
\hline 4 & $15(25.00 \%)$ & - & - & $16(26.66 \%)$ \\
\hline 5 & $7(11.66 \%)$ & - & - & \\
\hline 6 & $12(20.00 \%)$ & - & - & - \\
\hline
\end{tabular}

Table 3: Score earned by residents in different classes of questions

\begin{tabular}{|l|c|c|c|c|}
\hline Score Earned & $\begin{array}{c}\text { Class A } \\
(\mathbf{N = 6 0})\end{array}$ & $\begin{array}{c}\text { Class B } \\
(\mathbf{N = 6 0})\end{array}$ & $\begin{array}{c}\text { Class C } \\
\mathbf{( N = 6 0 )}\end{array}$ & $\begin{array}{c}\text { Class D } \\
\mathbf{( N = 6 0 )}\end{array}$ \\
\hline 0 & $1(3.33 \%)$ & $14(23.33 \%)$ & $7(11.66 \%)$ & $7(11.66 \%)$ \\
\hline 1 & $7(11.66 \%)$ & $26(43.33 \%)$ & $15(25.00 \%)$ & $7(11.66 \%)$ \\
\hline 2 & $6(10.00 \%)$ & $20(33.33 \%)$ & $21(35.00 \%)$ & $9(15.00 \%)$ \\
\hline 3 & $6(10.00 \%)$ & - & $17(28.33 \%)$ & $19(31.66 \%)$ \\
\hline 4 & $16(26.66 \%)$ & - & - & $18(30.00 \%)$ \\
\hline 5 & $11(18.33 \%)$ & - & - & \\
\hline 6 & $13(21.66 \%)$ & - & - & \\
\hline
\end{tabular}

Table 4: Comparison of mean score earned by residents in different classes

\begin{tabular}{|c|c|c|c|c|c|}
\hline \multicolumn{6}{|l|}{ Class A } \\
\hline $\begin{array}{l}\text { Average score in } \\
\text { Visit } 1 \\
(\text { Mean } \pm \text { SD) }\end{array}$ & SEM & $\begin{array}{l}\text { Average score in Visit } 2 \\
(\text { Mean } \pm \text { SD) }\end{array}$ & SEM & Mean Difference & $\mathrm{p}$ value \\
\hline $3.157 \pm 1.88$ & 0.24 & $3.9 \pm 1.70$ & 0.22 & $\begin{array}{l}-0.38 \\
-0 .\end{array}$ & $<0.0001-\mathrm{ES}$ \\
\hline \multicolumn{6}{|l|}{ Class B } \\
\hline $\begin{array}{l}\text { Average score in } \\
\text { Visit } 1 \\
(\text { Mean } \pm \text { SD) }\end{array}$ & SEM & $\begin{array}{l}\text { Average score in Visit } 2 \\
(\text { Mean } \pm \text { SD) }\end{array}$ & SEM & Mean Difference & $\mathrm{p}$ value \\
\hline $0.87 \pm 0.85$ & 0.11 & $1.10 \pm 0.75$ & 0.1 & -0.23 & $<0.0001-\mathrm{ES}$ \\
\hline \multicolumn{6}{|l|}{ Class $\mathrm{C}$} \\
\hline $\begin{array}{l}\text { Average score in } \\
\text { Visit } 1 \\
(\text { Mean } \pm \text { SD) }\end{array}$ & SEM & $\begin{array}{l}\text { Average score in Visit } 2 \\
(\text { Mean } \pm \text { SD) }\end{array}$ & SEM & Mean Difference & p value \\
\hline $1.58 \pm 1.15$ & 0.15 & $1.80 \pm 0.98$ & 0.12 & -0.21 & $<0.0001-\mathrm{ES}$ \\
\hline \multicolumn{6}{|l|}{ Class D } \\
\hline $\begin{array}{l}\text { Average score in } \\
\text { Visit } 1 \\
(\text { Mean } \pm \text { SD) }\end{array}$ & SEM & $\begin{array}{l}\text { Average score in Visit } 2 \\
(\text { Mean } \pm \text { SD) }\end{array}$ & SEM & Mean Difference & $p$ value \\
\hline $2.28 \pm 1.48$ & 0.19 & $2.56 \pm 1.34$ & 0.17 & -0.28 & $<0.0001-\mathrm{ES}$ \\
\hline
\end{tabular}




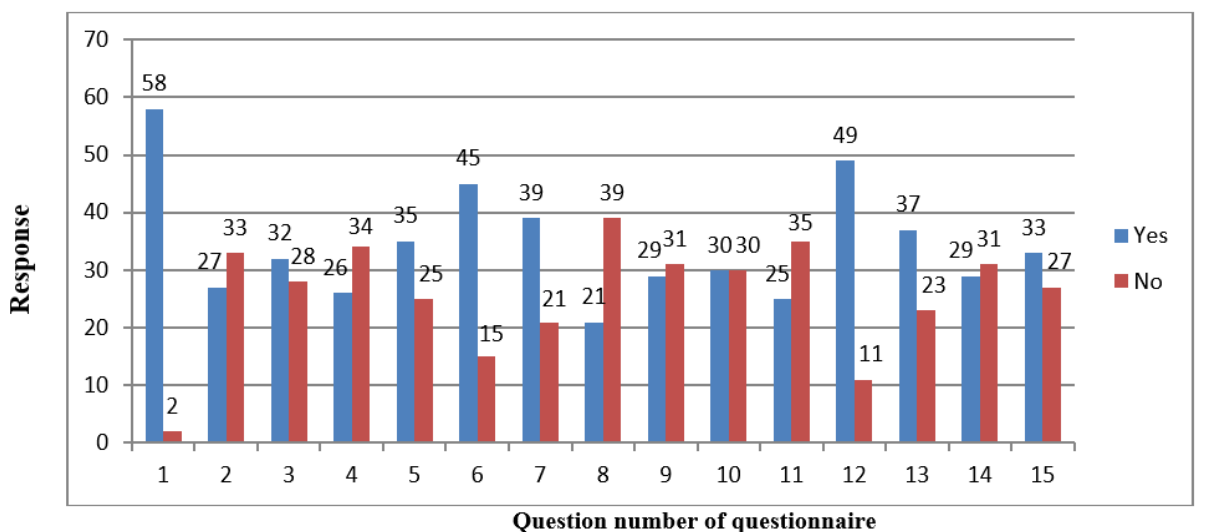

Fig. 2: Response shown by residents for each question

\section{Discussion}

This study was a questionnaire-based (fifteen questions) study, conducted in two visits (visit $1 \&$ visit 2 ) and was done on 60 residents (30 junior residents and 30 senior residents) to assess the knowledge and practice of pharmacovigilance among them. This study showed that the knowledge of pharmacovigilance was known to many residents but still reporting rate remains low in its context. $^{20,21}$ The awareness about PvPI was slightly lower among residents which leads to constructivism towards pharmacovigilance. This value was slightly higher in second visit which is similar in another study also. ${ }^{22}$ Almost all residents seemed to be aware of pharmacovigilance concept, still most of the participants were not able to define the term "Pharmacovigilance". Most of the participants were able to explain about ADRs and medication errors and were also able to give few details including some examples of ADRs they encountered in their fields of practice. Most of the residents were not aware of the reporting tools and reporting procedure. This was evident from the major mismatch between their testimonies of how often they come across ADRs versus the number of ADR reports collected from the hospital in that period. This was also similar to some other observational studies. ${ }^{23,24}$

Spontaneous reporting is an integral part of pharmacovigilance however knowledge and practice of this was on a lower side as observed in our study which can be attributed to heavy workload, lack of time, ignorance of the pharmacovigilance system in place, lack of feedback and tools. ${ }^{25}$ Most residents felt that ADRs were an important clinical aspect and felt they should be reported to avoid future tragedies caused by medications to prevent avoidable ADRs. They however, acknowledged that due to the heavy workload they faced in their day to day practice any additional work might not be very welcomed but nevertheless agreed for reporting. This was a positive response for the future activities of pharmacovigilance that can be undertaken in the hospital.

This study was further designed to assess the level of knowledge and awareness of residents regarding different spheres of pharmacovigilance. Four types of questions were incorporated into the given fifteen questionnaires of study to ascertain the level of awareness in different aspects. These four aspects comprised of basic knowledge of pharmacovigilance (question no. 1,3,4,6,7 and 8), reporting system of pharmacovigilance (question no. 2 and 5), possible benefits of pharmacovigilance (question no. 9,10 and 11), capability to give constructive opinion/recommendations over the improvement of system for pharmacovigilance (question no. 12,13,14 and 15). In visit 01 the awareness/knowledge of residents was assessed regarding different spheres of pharmacovigilance, followed by which they were sensitized and given knowledge regarding respective spheres. After about five months visit 02 was conducted and the respective residents were reassessed on same questionnaires. In the first visit, $70 \%$ and in second visit $76.65 \%$ of the residents were having average/above average basic knowledge of pharmacovigilance, whereas $6.66 \%$ in first visit and $3.33 \%$ in second visit of the residents were entirely unaware of concept of pharmacovigilance which is somehow in congruence to the study of Sewal RK et al, where $83.6 \%$ of the respondents were having average/above average basic knowledge of pharmacovigilance and $6 \%$ of the respondents were entirely unaware of concept of pharmacovigilance. ${ }^{[26]}$ In context of awareness of reporting system of pharmacovigilance $56.66 \%$ in first visit and $76.66 \%$ in second visit of the residents showed average/above average, whereas $43.33 \%$ in first visit and $23.33 \%$ in second visit were fully unaware of any reporting system. It indicates that there is lack of practice regarding reporting system of pharmacovigilance which is also an observation by another study. ${ }^{27}$ This staggering figure calls for the campaigns and training program for improvement in pharmacovigilance reporting system.

Underreporting is a serious concern and causes of underreporting are indifference to reporting, in addition to this lack of time due to too many activities in the clinical routine. ${ }^{24}$ This underreporting can be overcome by simplifying reporting pattern, documentation, toll free number assistance, financial incentives, creating more ADR centers and facilitating communication between healthcare professionals and pharmacovigilance centers. ${ }^{28,29}$ In first visit, $75 \%$ and in second visit $88.33 \%$ of the residents were having average/ above average knowledge while $25 \%$ in 
first visit and $11.67 \%$ in second visit were not having any knowledge regarding possible benefits of pharmacovigilance. $68.33 \%$ in first visit and $76.66 \%$ in second visit of the residents scored average/above average in context of their ability to give constructive opinion for the betterment of pharmacovigilance system. These figures suggest that there is need to escalate the level of awareness of residents and other healthcare professionals regarding reporting system of pharmacovigilance because $43.33 \%$ in first visit and $23.33 \%$ in second visit of the residents were found to have no knowledge of existence of any reporting system. Further, the mean score earned by residents in all four classes (A, B, C and D) of different spheres of pharmacovigilance were compared after both visits and were found to be extremely significant.

After completion of both visits, we also found that mean number of ADRs in three month increased after frequent training and sensitization. Similar pattern has also been observed by another study. ${ }^{30}$ Therefore, strategies must be developed to improve the acquaintance of these professionals for pharmacovigilance. There is a need for training and educational activities like CMEs for increasing the awareness about reporting of ADRs.

The strength of our study is that; in this study we have compared the knowledge and practice before and after the academic interventions. In addition, this study showed that frequent sensitization and training can improve the knowledge and practice regarding different spheres of pharmacovigilance. The limitation of our study is that responses from the participants could have been influenced by reporting bias. Moreover, the survey was only conducted on the resident doctors of this hospital with the assumption that the information given is uniform with all healthcare providers in this hospital which adds to another limitation.

\section{Conclusion}

This study concluded that knowledge and practice in different aspects regarding pharmacovigilance was improved among residents after giving proper sensitization. Hence, improved perception can remove the misconceptions, obstacles and barriers to the practice of pharmacovigilance for a better healthcare system. Largescale awareness of pharmacovigilance is required among different healthcare professionals for better understanding of this system. Moreover, special emphasis of pharmacovigilance in medical curriculum and its incorporation in medical internship is required to bring more awareness about rational usage of drugs; amongst the future doctors to minimize the adverse drug events or other drug related problems.

\section{Source of Funding}

None.

\section{Conflict of Interest}

None.

\section{Acknowledgement}

We are thankful to the resident doctors of IGIMS, Patna for their support.

\section{Ethics Committee Approval Obtained for this Study} Yes.

\section{References}

1. Ayalew MB, Megersa TN, Mengistu YT. Drug-related problems in medical wards of Tikur Anbessa specialized hospital, Ethiopia. J Res Pharm Pract. 2015;4(4):216-21.

2. The Importance of Pharmacovigilance Safety Monitoring of medicinal products [Internet]. United Kingdom: World Health Organization; 2002 [cited 3 April 2020]. Available from: https://apps.who.int/medicinedocs/pdf/s4893e/s4893e.pdf

3. Aronson JK. Adverse drug reactions- no farewell to harms. $\mathrm{Br}$ J Clin Pharmacol. 2007;63(2):131-5.

4. Pirmohammed M, James S, Meakin S, Green C, Park BK. Adverse drug reactions as a cause of admission to the hospital: prospective analysis of 18820 patients. Br Med J. 2004;329:15 9.

5. Ratan JL, Mangala L, Sukirti D. A study on adverse drug reactions in a tertiary care hospital of northeast India. Alex $J$ Med. 2017;53:151-6

6. Bouvy JC, De Bruin ML, Koopmanschap MA. Epidemiology of adverse drug reactions in Europe: a review of recent observational studies. Drug Saf. 2015;8:437-53.

7. Jayanthi CR, Renuka M, Panchaksharimath P. An observational Study to analyze the Adverse drug Reactions among the Elderly at A Tertiary Care Hospital. Biomed Pharmacol J. 201710(1):345-52.

8. Bates DW, Spell N, Cullen DJ, Burdick E, Laird N, Petersen LA. The costs of adverse drug events in hospitalized patients. Adverse Drug Events Prevention Study Group. JAMA. 1997;277:307-11

9. Pharmacovigilance Programme of India (PvPI) Updates: Performance Report 2018-19 [Internet]. Ghaziabad: Indian Pharmacopoeia Commission; 2019 [cited 2 February 2020]. Available from: https://ipc.gov.in/mandates/pvpi/pvpiupdates/8-category-en/646-annual-performance-report.

10. Kalaiselvan V, Prakash J, Singh GN. Pharmacovigilance programme of India. Arch Pharm Pract. 2012;3:229-32.

11. Vallano A, Cereza G, Pedros C, Agustí A, Danés I, Aguilera C, et al. Obstacles and solutions for spontaneous reporting of adverse drug reactions in the hospital. Br J Clin Pharmacol. 2005;60(6):653-8.

12. A Framework for Assessing the Economic Value of Pharmacovigilance in Low- and Middle-Income Countries Springer. [cited 2020 Jan 22]; Available from: http://link.springer.com/article/10.1007/s40264-014-01431/fulltext.html

13. Hussain MM, Girhepunje K, Pal R, Siddiqua SS. Incidence of Adverse Drug Reactions in a Tertiary Care Hospital: A Systematic Review and Meta-Analysis of Prospective Studies. Scholars Res Library. 2010;2(3):358-67.

14. Khan FA, Nizamuddin S, Najmul H, Mishra H. A prospective study on prevalence of adverse drug reactions due to antibiotics usage in otolaryngology department of a tertiary care hospital in North India. Int J Basic Clin Pharmacol. 2013;2:548-53

15. Ramesh M, Pandit J, Parthasarathi G. Adverse drug reactions in a south Indian hospital - Their severity and cost involved. Pharmacoepidemiol Drug Saf. 2003;12:687-92.

16. Khan SA, Goyal C, Chandel N, Rafi M. Knowledge, attitudes, and practice of doctors to adverse drug reaction reporting in a teaching hospital in India: An observational study. J Nat Sci Biol Med. 2013;4(1):191-6. 
17. Alan S, Ozturk M, Gokyildiz S, Avcibay B, Karatas Y. An evaluation of knowledge of pharmacovigilance among nurses and midwives in Turkey. Indian J Pharmacol. 2013;45(6):6168 .

18. Arias E, Schauman WS, Eschbach K, Sorlie PD, Backlund E. The validity of race and Hispanic origin reporting on death certificates in the United States. Vital Health Stat. 2 2008;148:1-23.

19. Kalaiselvan V, Gakhar S, Prasad T, Gupta SK, Singh GN. Spontaneous reporting of adverse drug reactions in geriatric patients in India. Natl J Physiol Pharm Pharmacol. 2014;3:225-8.

20. Herdeiro MT, Figueiras A, Polónia J, Gestal-Otero JJ. Physicians' Attitudes and Adverse Drug Reaction Reporting. Drug Saf. 2005;28(9):825-33.

21. Carbonin P, Bernabei R, Sgadari A. Is age an Independent risk factor of adverse drug reactions in hospitalized medical patients?. J Am Geriatr Soc. 1991;39(11):1093-9.

22. Gupta P, Udupa A. Adverse drug reporting and pharmacovigilance: Knowledge, attitude and perception among resident doctors. J Pharm Sci Res. 2011;3:1064-6.

23. Ganesan S, Vikneswaran G, Reddy KC, Subrahmanyam DK, Adithan C. A survey on knowledge, attitude and practice of pharmacovigilance towards adverse drug reactions reporting among doctors and nurses in a tertiary Care Hospital in South India. J Young Pharm. 2016;8(4):471-6.

24. Agarwal R, Daher AM, Ismail MN. Knowledge, practices and attitudes towards adverse drug reaction reporting by private practitioners from Klang valley in Malaysia. Malays J Med Sci. 2013;20(2):52-61.
25. Vallano A, Castañeda PF, Quijada Manuitt MA, Simon PC, Pedrós C, et al. Hospital Doctors' Views and Concerns about Pharmacovigilance. J Pharmacovigilance. 2015;3:160.

26. Saini VK, Sewal RK, Ahmad Y, Medhi B. Prospective observational study of adverse drug reactions of anticancer drugs used in cancer treatment in a tertiary care hospital. Indian J Pharm Sci. 2015;77:687-93.

27. Grootheest V, others. Attitudinal survey of voluntary reporting of adverse drug reactions. Br J Clin Pharmacol. 1999;48(4):623-7.

28. Kharkar M, Bowalekar S. Knowledge, attitude and perception/practices (KAP) of medical practitioners in India towards adverse drug reaction (ADR) reporting. Perspect Clin Res. 2012;3;3:90-4.

29. Gavaza P, Brown CM, Khoza S. Texas pharmacistse opinions on reporting serious adverse drug events to the Food and Drug Administration: a qualitative study. Pharm World Sci. 2010;32(5):651-7.

30. Fabbri S, Sichetti D, Di Giulio P. Efficacy of an education on adverse drug reaction reporting by nurses in nursing homes: A pre-post study. J Hosp Clin Pharm. 2016;2(3):6-13.

How to cite: Arya P, Mishra H, Kumar M, Shakur AA, Mohan L, Dikshit H. An observational, prospective and questionnaire-based study to assess awareness of pharmacovigilance among resident doctors in a tertiary healthcare centre of Bihar. Panacea J Med Sci. 2020;10(1):29-35. 